\title{
EDUCAÇÃO A DISTÂNCIA E O $1^{\circ}$ DA FAMÍLIA: O PENSAMENTO DE HABERMAS E A CONSTRUÇÃO DE UMA EDUCAÇÃO PARA A EQUIDADE NO CONTEXTO DA UAB
}

\author{
Ana Cristina Almeida Santana* \\ Lucia Maria Martins Giraffa**
}

\begin{abstract}
RESUMO
Este artigo apresenta o detalhamento da organização de uma investigação relacionada à Universidade Aberta do Brasil (UAB) em estudo de caso no estado de Sergipe, e a sua constituição como sujeito de direito, a partir da investigação de uma relação dialética baseada na racionalidade comunicativa de Jürgen Habermas. Ao buscarmos nos trabalhos correlatos a questão do $1^{\circ}$ na família (first in the Family) identificamos a mudança na concepção pessoal, familiar e sociocomunitária daqueles que são os primeiros na sua família a ter acesso à formação superior. Aliado a isto consideramos a oportunidade de cursar uma graduação na modalidade a distância $(\mathrm{EaD})$, como cenário emancipatório e de oportunidade para construção da cidadania e o acesso à educação superior. Os processos executados nesta fase piloto demonstram a oportunidade desta pesquisa, a sinalização da importância em ampliar as ofertas inclusivas associadas à educação superior, por meio da oferta de EaD.
\end{abstract}

Palavras-chave: $1^{\circ}$ na família (first in the Family). Universidade Aberta do Brasil. Habermas. EaD.

\section{ABSTRACT \\ DISTANCE EDUCATION AND FIRST-BORNS: USING THE THEORIES OF HABERMAS TO BUILD EQUITY EDUCATION WITHIN THE CONTEXT OF THE OPEN UNIVERSITY OF BRAZIL \\ This article takes a detailed look at the elaboration of a research study related to the Open University of Brazil (UAB), using the state of Sergipe as a case study. The aim is to highlight the important benefits of higher education offered by the UAB system that effectively incorporates first-born ("first in the Family") children. Data is analyzed using a methodology that focuses upon the dialectical relationship derived from Jürgen Habermas' concept of communicative rationality. The UAB courses not only}

\footnotetext{
* Mestre em Desenvolvimento e Meio Ambiente pela Universidade Federal de Sergipe (UFS). Doutoranda em Educação pela Pontifícia Universidade Católica do Rio Grande do Sul (PUCRS). Professora Assistente da Universidade Tiradentes (UNIT). Pesquisadora do Grupo de Pesquisa ARGOS/CNPq, da Faculdade de Educação (PPGEdu - PUCRS). Endereço institucional; Avenida Ipiranga, 6681, prédio 15 - $3^{\circ}$ andar. Porto Alegre-RS. CEP: 90610-900. Fone: (79) 9992-1103. anacrist11@yahoo.com.br ** Doutora em Computação pela Universidade Federal do Rio Grande do Sul (UFRGS). Pós-doutorado em Educação pela Universidade do Texas. Professora Titular da Pontifícia Universidade Católica do Rio Grande do Sul (PUCRS). Pesquisadora do Grupo de Pesquisa ARGOS/CNPq, da Faculdade de Educação (PPGEdu - PUCRS). Endereço institucional: Avenida Ipiranga, 6681, prédio 15 -3 $3^{\circ}$ andar. Porto Alegre-RS. CEP:90610-900. Fone: (51) 3320-3558. giraffa@pucrs.br
} 
offer first-born students access to higher education, but also provide an opportunity for students to develop a sense of citizenship. The processes carried out in this pilot phase revealed the importance of such research and emphasized the significant role of distance education in expanding access to higher education.

Keywords: First-born. Open University of Brazil. Habermas. Distance education.

\section{RESUMEN}

\section{EDUCACIÓN A DISTANCIA Y EL $1^{\circ}$ DE LA FAMILIA: EL PENSAMIENTO DE HABERMAS Y LA CONSTRUCCIÓN DE UNA EDUCACIÓN PARA LA EQUIDAD EN EL CONTEXTO DE LA UAB}

Este artículo presenta los detalles de la organización de una investigación relacionada a la Universidad Abierta de Brasil (UAB), en estudio de caso en el estado de SergipeBrasil, y su constitución como sujeto de derecho, a partir de la investigación de una relación dialéctica basada en la racionalidad comunicativa de Jürgen Habermas. Buscando, en trabajos relacionados la cuestión del $1^{\circ}$ en la familia (first in the Family), se identificó el cambio en la concepción personal, familiar y socio-comunitaria de aquellos que son los primeros en su familia en tener acceso a la formación superior. Unido a eso, se consideró la oportunidad de cursar una graduación en la modalidad a distancia $(\mathrm{EaD})$ como escenario emancipatorio y como oportunidad para la construcción de la ciudadanía por el acceso a la educación superior. Los procesos ejecutados en esta fase piloto demuestran la oportunidad de esta investigación, la señalización de la importancia de ampliar las ofertas incluyentes asociadas a la Educación Superior, por medio de la oferta de EaD.

Palabras-clave: $1^{\circ}$ en la Familia (first in the Family). Universidad Abierta do Brasil. Habermas. EaD.

\section{Introdução}

A Educação a Distância (EaD) tem se consolidado como uma modalidade de ensino e de aprendizagem com potencial para propiciar a efetivação do direito humano fundamental à educação superior e à construção da cidadania em locais ou regiões marcadas pela pobreza, miséria, carência de recursos e de ensino presencial, tradicionalmente exemplos de processo de exclusão social, como o Nordeste brasileiro. Logo, acredita-se que a EaD pode auxiliar a diminuir os efeitos de tal exclusão no que tange à questão educacional, e acredita-se que a criação da Universidade Aberta do Brasil (UAB) trouxe outras perspectivas para ampliação dos processos inclusivos no que concerne à educação superior.

[...]o Sistema UAB propicia a articulação, a interação e a efetivação de iniciativas que estimulam a parceria dos três níveis governamentais (federal, estadual e municipal) com as universidades públicas e demais organizações interessadas, enquanto viabiliza mecanismos alternativos para o fomento, a implantação e a execução de cursos de graduação e pós-graduação de forma consorciada. Ao plantar a semente da universidade pública de qualidade em locais distantes e isolados, incentiva o desenvolvimento de municípios com baixos IDH e IDEB. Desse modo, funciona como um eficaz instrumento para a universalização do acesso ao ensino superior e para a requalificação do professor em outras disciplinas, fortalecendo a escola no interior do Brasil, minimizando a concentração de oferta de cursos de graduação nos grandes centros urbanos e evitando o fluxo migratório para as grandes cidades. (UNIVERSIDADE ABERTA DO BRASIL, 2014).

Mesmo com os resultados obtidos nas avaliações do Exame Nacional de Desempenho de Estudantes (ENADE), a EaD ainda enfrenta críticas e resistência de setores tradicionais da Educação, 
como aqueles de cunho positivista, marcados pela lógica formal, atribuindo a esta modalidade baixa qualidade de ensino e mantendo os três mitos: é mais fácil estudar na $\mathrm{EaD}$, é mais barato eo tempo de formação é menor. Estes equívocos têm levado muitas pessoas a não optarem por estudar nesta vertente e esquecem-se de que o estudo nesta modalidade vai requerer do aluno mais disciplina, autonomia e força de vontade (perseverança). O tempo é regulado pelo MEC e não existe "mágica" para diminuir a estrutura de um curso. E, por fim, o custo é menor. Mesmo? Para quem? Para o ofertante? Para o aluno? Mitos. O que existe é um deslocamento de custos que são distribuídos nas diversas edições (investimentos para organização e estruturação do curso) e na infraestrutura que fica a cargo do aluno (Internet, local para estudar e organização do seu acervo de materiais).

Além dos mitos oriundos do desconhecimento do que significa estudar na $\mathrm{EaD}$ com qualidade, existe um histórico desabonador no que concerne à oferta de cursos por instituições não cuidadosas da qualidade das suas ofertas. Segundo Netto, Giraffa e Faria (2010), aquelas que optaram por oferecer cursos para produção em "massa" de certificados, sem o devido compromisso com a aprendizagem efetiva de seus alunos. Apesar dessas críticas, a EaD é uma realidade no cenário brasileiro, ocupando espaços e revelando-se como um instrumento capaz de propiciar a efetivação do direito humano fundamental à educação e ao exercício da cidadania.

Ainda que sofra críticas, cresce a aposta e o investimento do poder público na $\mathrm{EaD}$ como uma modalidade de se fazer Educação, que vem se revelando uma verdadeira quebra de paradigma ${ }^{1}$ na educação superior, com a implementação de um método de aprendizagem específico e importante mecanismo capaz de promover a inserção social, fato que, coerente com o atual sistema jurídico brasileiro, justificou a criação da Universidade

1 Thomas Khun (1978, p. 219), em sua obra intitulada Estrutura das Revoluções Científicas, foi quem melhor designou o entendimento de paradigma como um fator produto da história e do enquadramento dos processos de construção do conhecimento científico, ou melhor, "um paradigma, é aquilo que os membros de uma comunidade partilham e, inversamente, uma comunidade científica consiste em homens que partilham um paradigma", e define "o estudo dos paradigmas como o que prepara basicamente o estudante para ser membro da comunidade científica na qual atuará mais tarde" (KHUN, 1978, p. 31).
Aberta do Brasil (UAB) no final do ano de 2005.

Cabe ressaltar que os dados do ENADE também apontam que desde a criação das políticas inclusivas, tais como PROUNI, estima-se que em torno de $85 \%$ da população que hoje frequentam as universidades brasileiras são first in the Family. No entanto, a concentração ainda se dá nas regiões sul e sudeste, nas capitais e grandes centros, onde a oferta presencial é maior. A opção de estudar na modalidade virtual (EaD) nas regiões Norte e Nordeste, especialmente no interior, representa a oportunidade de ter efetivo acesso à educação superior. Se as políticas inclusivas e de acesso à educação superior produziram efeitos positivos no aumento do número de estudantes que hoje frequentam ou já frequentaram faculdades, centros universitários ou universidades, a oferta de vagas via UAB terá capilaridade maior.

Outro aspecto que buscamos colaborar reside na importância da EaD como alternativa, cada vez mais consolidada, para cenários heterogêneos como o caso do Brasil, seja por má distribuição econômica da renda, seja pelas condições geográficas e continentais do nosso pais.

Para o desenvolvimento desta pesquisa optou-se pela abordagem qualitativa em razão das características deste tipo de estudo, que permite privilegiar o ambiente natural como fonte de investigação. A partir de diferentes enfoques teóricos, epistemológicos e metodológicos, buscou-se identificar com a pesquisa qualitativa, nos termos de Gibbs (2009), o seguinte: a) as experiências, interações e documentos em seus contextos particulares; b) os conceitos serão desenvolvidos e refinados no decorrer da pesquisa; c) a conjugação, adaptação e ajustes dos métodos existentes ou novos métodos e abordagens desenvolvidas; dentre outras posturas flexíveis e abertas ao fenômeno a ser estudado. Do ponto de vista de procedimentos técnicos, este estudo foi desenvolvido a partir de um Estudo de Caso (YIN, 2001) envolvendo um olhar sobre a contribuição dos dez anos da UAB no estado de Sergipe.

Este artigo apresenta a organização da pesquisa cujo objetivo geral é de investigar a percepção dos egressos, que são os primeiros na família a se graduarem pela UAB em Sergipe, acerca da formação recebida e contribuição desta para a melhoria de 
sua vida pessoal, familiar, social, profissional e do sentimento de cidadania.

Buscou-se, neste texto, apresentar o contexto da investigação, a problematização, os trabalhos correlatos utilizados para ancorar as reflexões propostas, o processo de construção dos instrumentos, a forma como foi conduzida a análise dos resultados alcançados na $1^{\mathrm{a}}$ etapa, onde fez-se um piloto investigativo buscando validar instrumentos e processos, considerando um recorte no cenário de oferta em todos os polos do estado de Sergipe.

Os resultados nos levaram a termo a sequência da pesquisa em caráter mais abrangente a fim de reforçar nossa premissa de pesquisa, baseada no pressuposto de que se mais de $80 \%$ da população que hoje frequenta o ensino superior brasileiro teve acesso à educação superior por conta das políticas inclusivas, a oferta de EaD por meio do sistema UAB amplia o espaço de inclusão.

\section{Saber histórico e dialético na Educação a Distância: o pensamento de Habermas}

De início, pode soar desarrazoado falar em dialética habermasiana na $\mathrm{EaD}$, pois, como se costuma arguir de forma prematura, o aluno da EaD se mostra, em regra, como um sujeito isolado, autônomo e com possibilidades restritas de comunicação, fatores objeto de críticas contundentes quanto à validade e qualidade dos cursos a distância. Contudo, corroborando com Prestes (1996, p. 09), compreendemos que "a racionalidade presente no agir comunicativo é uma das abordagens mais produtivas para configurar uma nova face à educação, que não só permita compreender os problemas que a afligem, como também anuncie uma ação racional possível".

E, assim como Prestes (1996), defendemos a possibilidade de uma ação emancipatória pela educação a distância, a partir da confiança na constituição de um sujeito de Direito, cuja racionalidade transcenda a instrumental e a do procedimento, e da crença na possibilidade de uma ação pedagógica complexa que conduza à liberdade, equidade $\mathrm{e}$ emancipação do sujeito.

O paradigma adotado na educação e, em especial, na EaD é o decorrente de uma "racionalidade que se fragmenta numa multiplicidade de esferas, que se mantém como saberes incomunicáveis, como mônadas incomunicáveis", onde falta articulação legítima entre os envolvidos, não se reflete sobre as tradições culturais e acaba por esgarçar o "tecido que mantém a educação vinculada à produção da vida humana" (PRESTES, 1996, p. 10).

Crê-se que esse é o grande desafio a ser enfrentado pela $\mathrm{EaD}$ na contemporaneidade, ou seja, como possibilitar que o sujeito desenvolva uma dimensão cognitiva autoconsciente, autônoma e crítica?

No processo educativo contemporâneo, inclusive no contexto da $\mathrm{EaD}$, a racionalidade habermasiana emerge da dupla face do processo educativo: de um lado como produtor de um sujeito autônomo, um processo individual, e, de outro, um processo de construção coletiva, de humanidade. Sendo assim, é necessário vincular a racionalidade na $\mathrm{EaD}$, explicitando as categorias que viabilizam a formação da identidade racional dos sujeitos a partir do interesse em uma comunicação livre de coações (PRESTES, 1996).

Para Habermas (1999), o projeto técnico (empírico-analista) não se sustenta mais, devendo surgir um projeto prático (histórico hermenêutico), necessário ao projeto emancipatório (ciência crítica). Com Habermas (1999), concebemos "uma prática de autodeterminação cidadã”, com a colocação de temas como a democracia e a própria política no centro do "paradigma do diálogo", fato que torna relevante o aprofundamento do "modelo da democracia deliberativa", a comunicação humana manifestada ao longo da história das sociedades modernas racionalizadas.

Cuida-se, para Estêvão (2006, p. 88), da

[...] concepção dialógica da política, entendida como um processo e razão e não exclusivamente de vontade, como um processo de persuasão argumentativa e não exclusivamente de poder, dirigido para a consecução de um acordo relativo a uma forma boa ou justa, ou pelo menos aceitável, de ordenar aqueles aspectos da vida que se referem às relações sociais $\mathrm{e}$ à natureza social das pessoas.

$\mathrm{Na}$ essência dessa concepção, têm-se a ideia de participação política com cidadãos iguais, ou melhor, a legitimidade das decisões pressupõe participação democrática, participação popular, democraticamente livre e entre iguais. 
Para tanto, o cidadão tem que estar preparado, formado, educado para participação na esfera pública do discurso racional, em prol do bem comum (HABERMAS, 1999). Essa formação ou bildung exige flexibilidade e dinamismo, onde as ações democráticas "deliberativas exigem ir além do voto, mobilizando a capacidade de questionar e mudar as preferências pré-fixadas, próprias ou alheias, pela via da (s) razão (ões)" (ESTÊVÃO, 2006, p. 89).

A formação a que faz alusão Habermas (1999, p. 348) depende dos recursos do "mundo da vida" - ou seja, de uma cultura espontânea, livre e natural, assim como de uma socialização política de tipo ilustrado, como as típicas "das iniciativas das associações conformadoras da opinião", que juntas se constituem e regeneram naturalmente.

Ciente da complexidade e dificuldade da obtenção do consenso, a abordagem habermasiana possui o "mérito de reforçar a ética da justiça e dos direitos, uma vez que destaca a questão da legitimação" sobre os valores elencados como bens comuns. Ao deliberar, exige-se que "as partes oponentes ofereçam e estejam abertas a razões e se respeitem mutuamente, ou seja, que mobilizem o seu poder comunicativo", fato que permite a convivência entre dissonantes morais, de forma respeitosa e construtiva (ESTÊVÃO, 2006, p. 89-90).

A concepção habermasiana, como aduz Estêvão (2006), não se encontra imune a críticas. Uma crítica a Habermas que merece destaque é a que gira em torno do dissenso, o conflito sobre o que são bens comuns, que embora sem soluções, são inerentes às políticas democráticas. E, por fim, outra debilidade da concepção discursiva habermasiana apontada por Estêvão (2006) é no tocante a uma suposta menor atenção não só aos aspectos da diferença, mas também aos do desejo e da justiça afetiva.

$O$ fato é que a igualdade formal ${ }^{2}$ inexiste, nem todos estão na mesma situação ou patamar de desempenhar plenamente uma comunicação, além do fato de o argumento não ser o único modo de comunicação cidadã ou política e de poder a se expressar de muitos modos (ESTÊVÃO, 2006). Contudo, acreditamos que a construção de uma educação para a equidade passa pela

\footnotetext{
2 Aristóteles (2008), quanto à equidade, já afirmava que se deve tratar igual os iguais e desigual os desiguais.
}

[...] aceitação e respeito pelo Outro na sua singularidade (individual e social), a interdependência significante, a importância da emoção ou dos actos perlocutórios (retórica), o direito do Outro contar a sua história com a mesma autoridade e o mesmo valor do ponto de vista da situação comunicativa tornam-se elementos-chave da sua proposta de uma "democracia comunicativa", mais atenta à ética do cuidado assim como aos direitos humanos como expressão suprema do cuidado e da solidariedade para com o Outro. (ESTÊVÃO, 2006, p. 90).

Com efeito, no pleno desenvolvimento de uma ação pedagógica comunicativa e mediada por recursos digitais, comprometida com a construção de cidadãos, de sujeitos de Direito, a interação não pode obscurecer as diferenças, os interesses, tampouco as diferentes posições sociais dos sujeitos envolvidos. E é esse reconhecimento da diferença e do que não é comum que desafia a própria argumentação e que leva a invocar a justiça e a "reciprocidade assimétrica" entre perspectivas dos sujeitos, uma vez que cada um tem a sua história que "transcende a copresença de sujeitos em comunicação" e cada posição social é estruturada pela configuração de relações entre outras posições, o que dá a cada locação um sentido específico e irreversível (YOUNG, 1997 apud ESTÊVÃO, 2006, p. 90-91).

Nesse sentido, todo e qualquer processo comunicativo nos termos propostos pelo agir comunicativo de Habermas deve, antes de tudo, respeitar amplamente o pluralismo, seja histórico, cultural, de ideias, de gênero etc., como condição elementar à construção de uma formação justa e equânime. Assim, entendemos que não existe óbice para que, numa ação pedagógica comunicativa mediada por recursos digitais, ou melhor, na $\mathrm{EaD}$, desenvolva-se uma racionalidade emancipatória comprometida com a equidade, a justiça, o pluralismo de ideias, o respeito à dignidade da pessoa humana, bastando para isso motivar os docentes a instigarem os discentes, provocando-os e preparando-os ao exercício da cidadania, estimulando a participação destes na vida pública, por meio da argumentação e da racionalidade ético-comunicativa.

Bourdieu (1976), em sua teoria sobre os capitais, apresenta e distingue várias espécies de capital, vários poderes que, no caso da educação, passam a definir as probabilidades de ganho individual, 
social, econômico, simbólico, político etc., que contribuem para determinar depois a posição do indivíduo na sociedade. No caso, o primeiro graduado da família ou first in the Family, oportunidade em que estudamos que tipo de "capital" esse sujeito poderá passar a desempenhar na sua comunidade.

Com uma $\mathrm{EaD}$ voltada à dialogicidade, comprometida com o estímulo à dialeticidade, possibilitando a oitiva das diversas vozes, dos diferentes olhares e argumentos, em síntese, do pluralismo de ideias (raciais, étnicas, sexuais, religiosas etc.), entendemos como real a concretização e construção de novos habitus ou padrões éticos mínimos e universais como a justiça, equidade, liberdade, igualdade e até, quem sabe, a tão sonhada solidariedade.

Esse propósito é naturalmente complexo, especialmente em tempos de sociedade global, internacionalização, mundialização, capitalismo global, contudo é uma alternativa que se mostra como uma arquitetura viável e possível, não a única, para a implementação de educação presencial ou a distância crítica que instigue a participação política e democrática, e promova a emancipação dos sujeitos, com destaque para as invariantes axiológicas ou o mínimo ético universal, resultante de um esforço dialógico na transformação desses atores em protagonistas, autores ou sujeitos de direito emancipados, comprometidos com uma ética pública resultante do diálogo inter e/ou multicultural dos direitos humanos.

Para a incorporação dos pressupostos argumentativos da ética discursiva universal habermasiana, inerentes à comunicação entre os homens, padrões de comportamento devem ser incluídos, como, por exemplo: a) a não contradição - onde cada sujeito deve manter-se coerente ao expressar-se verbalmente, evitando a atribuição de significados linguísticos diferentes em um mesmo diálogo; b) autenticidade e adição de tópicos - o interlocutor tem que ter a crença no que acredita e defende, podendo aditar elementos que entender como razoáveis e pertinentes à discussão; e c) competência, questionamento, introdução de novas asserções, autoexpressão e não coerção.

Em síntese, na $\mathrm{EaD}$ deve-se incentivar, estimular e possibilitar diálogos produtivos entre os alunos, entre os professores e os alunos e, inclusive, entre os professores das diversas disciplinas e cursos, de forma que sejam propiciadas e facilitadas argumentações e contra-argumentações claras, amplas e capazes de se chegar a um consenso genuíno que identifique os desejos e necessidades dos envolvidos e atenda aos parâmetros mínimos necessários a uma convivência pacífica.

Nesse sentido, não há como não acreditar que o sujeito isolado, com todo o seu "mundo da vida", como diz Habermas (1999), a sua experiência de vida e capital cultural, dotado de elementos materiais e digitais. Aspectos estes que lhe possibilitam a abordagem EaD, uma vez que exercem seu potencial comunicacional com outros sujeitos, com esperadas e naturais divergências culturais, sociais, econômicas e políticas, determinado e responsável por suas ações, interagindo e dialogando, argumentando e contra-argumentando, numa relação dialética educacional.

Esse espaço proporciona o esclarecimento ou a ilustração, fazendo com que saia da menoridade e atinja a maioridade, nos termos de Kant (2008), tornando-se assim um sujeito da história.

Ressalte-se, neste ponto, que não se está aqui fazendo uma apologia acrítica do pensamento kantiano, mas entende-se que alguns conceitos kantianos, em especial o de esclarecimento (KANT, 2008), ainda encontram ressonância hoje, em época de cibereducação, ou de educação a distância mediada por recursos digitais, e alguns fragmentos daquele texto merecem destaque e discussão. São eles:

Uma época não pode se aliar e conspirar para tornar a seguinte incapaz de estender seus conhecimentos (sobretudo tão urgentes), de libertar-se de seus erros e finalmente fazer progredir o Esclarecimento. Seria um crime contra a natureza humana, cuja vocação original reside nesse progresso; e os descendentes terão pleno direito de rejeitar essas decisões tomadas de maneira ilegítima e criminosa.

\section{$[\ldots]$}

Um homem pode, a rigor, pessoalmente e, mesmo então, somente por algum tempo, retardar o Esclarecimento em relação ao que ele tem a obrigação de saber; mas renunciar a ele, seja em caráter pessoal, seja ainda mais para a posteridade, significa lesar os direitos sagrados da humanidade, e pisar-lhe em cima. (KANT, 2008, p. 05-06). 
Assim, urge clamar por uma cibereducação crítica pulsante e concreta que ocorra nas práxis pedagógicas brasileiras.

Esse é o paradoxo do século, esse é o desafio contemporâneo! Não se pode mais fechar os olhos para a $\mathrm{EaD}$, para a cibereducação. A cibereducação, nesse momento histórico, tem que assumir seu papel de conduzir esse processo com uma proposta educacional que ao mesmo tempo seja moralizante, resgatando o conceito de esclarecimento kantiano, e, por mais complexo que possa parecer, crítica e dialética, no paradigma habermasiano.

Para a reconstrução da racionalidade na prática cotidiana, faz-se necessário aos "professores desmistificar os tabus relacionados ao uso de tecnologias em sala de aula", buscando sempre reciclar suas concepções visando atender aos anseios dos discentes ávidos de "conteúdos" diversos e elementares para a mudança de suas vidas e desenvolvimento social e individual (GIRAFFA, 2010, p. 37), enfim, que se insiram na cibereducação.

Mudanças em que o ciberdocente da EaD deverá perpassar pela criação de estímulos ao raciocínio do discente, fazendo com que este passe a pensar criticamente e possibilite a sua formação cidadã e de sua autonomia, ${ }^{3}$ por meio de uma aprendizagem mais humana, interativa e que conduza ao processo de reconhecimento ${ }^{4}$ e criatividade dos estudantes em regra podada no sistema clássico, esse é o grande desafio.

Uma educação que tenha como fundamento

\footnotetext{
3 Segundo Flickinger (2011, p. 07-08), a "Pedagogia desde sempre vinha buscando caminhos que levassem a pessoa a encontrar seu lugar social, intelectual e cultural na comunidade [...] A ideia de autonomia nasceu junto aos ideais defendidos pelo iluminismo. Ao apostar na sua autonomia e liberdade, o homem moderno libertou-se da camisa-de-força da sociedade medieval, assumindo, ele mesmo, a responsabilidade de suas ações. [...] [E que a]tarefa de tirar a pessoa da menoridade, dando-lhe a competência de decidir sobre seus interesses e sua atuação, sem intromissão dos outros, marca o centro da argumentação kantiana.[...] que autonomia em seu sentido originário grego, significa a capacidade de dar a si mesmo as normas de comportamento e atuação.

4 A partir dos trabalhos de Honneth (2009), a teoria do reconhecimento vem ocupando cada vez mais espaço nas discussões das Ciências Sociais e da Pedagogia, a partir dos filósofos idealistas e, em especial, pela luta de Hegel pelo reconhecimento como "fermento do desenvolvimento social”. . "[...] reconhecer alguém não significa simplesmente conhecê-lo, mas 'referir-se, simultaneamente, à liberdade do outro que, por sua vez, atua como instância de reconhecimento"”. Cuida-se assim de uma relação recíproca, onde o "ato de reconhecer vê no outro também um indivíduo autônomo, ao qual se atribui a capacidade de reconhecer" (FLICKINGER, 2011, p. 10).
}

ético-moral o direito ao acesso e o desenvolvimento da cidadania deve ser pautada na diretriz básica que vise à "conquista da maioridade, autonomia e liberdade pessoais" e o respeito às diferenças, ou também, à educação cabe assumir, antes de tudo, o desafio de ajudar o educando a alcançar uma postura de reconhecimento social e, consequentemente propiciar a conquista da autoestima e autonomia individual (FLICKINGER, 2011, p. 11).

Assim, tornam-se importantes as relações entre indivíduo e sociedade. Ou seja, a educação deve "ser pensada numa perspectiva de crítica e de alteração das relações sociais, e as possibilidades idealizadoras, com suas utopias secularizadas" (HERMANN, 1999, p. 41), fator que conduzirá à legitimação da educação.

E ainda, quando se trata do first in the Family, ou do primeiro graduado da família a concluir uma faculdade, por intermédio da $\mathrm{EaD}$, como no caso sob exame, da Universidade Aberta do Brasil em Sergipe, acredita-se que esse impacto torna-se muito mais evidente e importante.

Acreditamos que natural e potencialmente um sujeito autônomo, determinado, organizado e disciplinado poderá sair da "menoridade" bem orientado e utilizando dos recursos que a educação a distância permite, como chats, fóruns, arquivos, vídeos, orientações, autoavaliações, enfim, espaços onde o debate, a discussão e a reflexão deverão ser estimulados.

Ou como preferiu chamar Platão (2006), que o indivíduo saia do estágio das "sombras", mas terá, sim, um efeito desencadeante do tipo "dominó", em todos aqueles que lhe circulam, seja na família, na comunidade etc.

\section{First in the Family, o $1^{\circ}$ da família a fazer graduação: desafios e oportunidades}

Sobre ofirst in the Family, ou o primeiro da família, primeiro graduado, estreante a realizarem um curso superior, como serão chamados neste artigo, pode-se encontrar uma farta literatura nos Estados Unidos da América, onde esses alunos contam com alguns organismos de apoio e aconselhamento, em que egressos que passaram por situação semelhante compartilham histórias pessoais, dicas de planeja- 
mento para aqueles que enfrentarão o desafio de cursar um curso superior de forma pioneira em suas famílias.

Estudo realizado pelo Higher Education Research Institute (HERI), da University of California, Los Angeles, analisou o decréscimo da proporção de estudantes de nível superior de primeira geração nos anos de 1971, 1981, 1991, 2001 e 2005, de estudantes nativos dos Estados Unidos da América e os de origem e/ou descendência latina, africana e brancos (HIGHER EDUCATION RESEARCH INSTITUTE, 2014, tradução nossa).

Em abril de 2007, o referido instituto publicou um sumário do trabalho onde elenca, dentre outras conclusões, as seguintes: a) Características Demográficas -a partir de 1971, a proporção de estudantes de primeira geração, comparada com a de estudantes de ensino superior que não se enquadram nessa categoria, tem diminuído, fato que reflete os crescentes níveis de educação superior entre a população dos EUA; b) Já as diferenças étnicas ainda são preocupantes, os afro-americanos de primeira geração estão em declínio desde 1975 , mas os hispânicos continuam a ter menos educação universitária; c) Quanto ao incentivo parental, restou patente a tendência, desde 1971, de estímulo familiar na realização da faculdade pelos alunos de primeira geração; e d) Experiência de trabalho e considerações financeiras - percentuais elevados comprovaram que os estudantes universitários de primeira geração trabalharam mais de 20 horas semanais durante o ensino médio, e bem mais da metade $(55 \%)$ continuam a trabalhar para poder pagar a faculdade, sendo uma das expectativas citadas por esses estudantes a esperança de "ganhar mais dinheiro" a partir da conclusão do curso superior (HIGHER EDUCATION RESEARCH INSTITUTE, 2014, tradução nossa).

Além dos estudos norte-americanos, merecem ressalva os seguintes trabalhos: a) o de Gofen (2009), da Universidade Hebraica, publicado em fevereiro de 2009, intitulado Capital familiar: como a primeira geração de estudantes do ensino superior quebra o ciclo intergeracional; e b) o de autoria de Cecilia Albert (2000), da Universidade de Alcalá, Espanha, publicada no ano 2000, com o título Demanda da educação superior na Espanha: a influência dos sinais de mercado e antecedentes familiares.
No primeiro trabalho acima referido, Gofen (2009) afirma que indivíduos que alcançam uma educação superior, cujos pais não possuem formação superior, incorporam e realizam uma mobilidade social.Os chamados "primeira geração de estudantes de nível superior" muitas vezes são sucessores das vontades ou sonhos de seus antecedentes, enfrentam muitos desafios, contam com o auxílio de seus familiares. Concluiu-se, a partir do estudo com 50 (cinquenta) estudantes israelenses de primeira geração, que eles promovem uma "quebra" no ciclo intergeracional da herança do nível educacional ao envolver a vida familiar no dia a dia, especialmente a educação alcançada pela mãe, onde se prioriza a educação através de recursos não materiais, ao qual conceitua como "capital familiar", destacando uma melhor compreensão desse papel para a promoção de políticas públicas eficientes.

Bukoski (2012) afirma que, nos últimos 60 anos, os Estados Unidos ampliaram profundamente o acesso ao ensino superior, verificando-se nesse período diferenças no acesso e permanência de certos grupos minoritários e desfavorecidos, fator este que leva a limitações futuras, como o ganho de benefícios econômicos individuais e sociais, com o surgimento de maiores taxas de emprego e salários.

Dentre os benefícios econômicos, Bukoski (2012) destaca: maior grau de realização e satisfação no trabalho; diminuição de vícios como fumo, drogas, etc.; e ainda a menor dependência de políticas públicas de assistência social.

Segundo essa autora, esses benefícios justificam a concentração de esforços no incentivo dos alunos primeiros da família a se aventurar no mundo da educação superior, a despeito de uma miríade de desafios que enfrentarão ao longo caminho para o sucesso (BUKOSKI, 2012).

Sobre os alunos primeiros da família a cursarem uma faculdade, Bukoski (2012) aduz que, nos últimos 40 (quarenta) anos, sólida literatura norte-americana pode ser destacada, especialmente sobre as características demográficas - locais onde esses estudantes tendem a ir para a faculdade; os desafios gerais que enfrentam; a probabilidade de obtenção do diploma desejado.

Contudo, ressalta Bukoski (2012) que poucos estudos foram além da mera classificação dos estudantes como de "primeira geração" a cursar uma 
faculdade; raros estudos mostram as "experiências" desses alunos na faculdade, restringindo-se apenas a distingui-los dos alunos que não são os primeiros da família a cursarem uma universidade. Esses estudos mostram que os primeiros são de várias culturas e possuem múltiplas identidades e que ainda são uma categoria social ou um grupo muito heterogêneo; que grande parte das pesquisas é de cunho quantitativo, deixando de analisar as diferenças culturais entre esses alunos e os variados aspectos das suas identidades, mascarando assim as diferenças existentes entre os alunos de primeira geração.

Segundo Bukoski (2012), boa parte dos trabalhos destacam os fenômenos com ênfase no impacto de outras variáveis culturais (raça/etnia, gênero, idade, habilidades ou o sistema de status econômico), restando patente que, nos Estados Unidos, os primeiros são: a) pertencentes a um grupo étnico-minoritário; b) possuem um status socioeconômico baixo; c) são em maioria do sexo masculino; c) possuem carências em sua formação acadêmica; d) apresentam cumulativa desvantagem em rendimento acadêmico, vivem em situações de risco; e) são vítimas de opressões sistêmicas.

Em síntese, poucos trabalhos cruzam essas características de forma significativa e qualitativa, mascarando assim as vozes, vivências e esperanças dos alunos primeiros da família a cursarem uma faculdade, suas múltiplas identidades, interpretações, vivências, ou, nas palavras da própria Bukoski (2012, p. 03), "traçam uma imagem em pinceladas largas, sem nuances e detalhes" dos primeiros, sob a bandeira da objetividade científica, a meritocracia, o daltonismo e neutralidade, dando margem ao encobrimento do poder e privilégio de grupos dominantes.

Assim, buscando suprir uma lacuna na literatura sobre os alunos de primeira geração a cursar uma faculdade, Bukoski (2012), de forma inovadora, desenvolveu um trabalho para entender melhor a experiência desse heterogêneo grupo, com o intuito de estudar as experiências individuais, numa análise narrativa e visual de textos e elementos visuais, contribuindo assim para a construção de uma metodologia que integra esses dois aspectos: narrativo e visual.

\section{Organização da pesquisa e achados}

Ao propor um olhar sobre a unidade de estudo, a UAB em Sergipe busca entender a percepção dos egressos acerca da contribuição da UAB na sua formação e na construção da sua cidadania, expressa pelos indicadores como melhoria da qualidade de vida, inserção no mercado de trabalho e ampliação da percepção crítica dos egressos.

Assim, o levantamento das vivências dos egressos dos cursos realizados pela $\mathrm{UAB}$, a partir da realização desses cursos, se reflete na sua capacidade de compreender a realidade e de atuar na sociedade em que vive, com indicativo de melhoria nas condições de vida e trabalho desses alunos. Para completar o cenário investigativo inclui-se na pesquisa os dados oriundos da compreensão e engajamento dos coordenadores dos polos e dos tutores acerca dos $1^{\circ}$ na família.

A fim de validar instrumentos e processos da pesquisa visando maior compreensão da realidade do fenômeno a ser estudado, e de forma a facilitar a análise de documentos, foi feita a coleta de opiniões via questionário online, como coordenador do polo, alunos e tutores dos cursos ofertados pela UAB de um dos polos do estado de Sergipe (Universidade Federal de Sergipe). Para poder compor o mosaico de atores que concorrem para investigar a percepção dos egressos que são os primeiros na família a se graduarem pela UAB em Sergipe, foi necessário criar três instrumentos de coleta de dados:

a) Um questionário enviado aos alunos egressos dos cursos;

b) Um questionário enviado aos tutores dos polos;

c) Um questionário enviado aos coordenadores dos polos.

Os questionários possuem perguntas fechadas (organizadas em escolhas simples e escolhas múltiplas) e poucas questões abertas. Usou-se como ferramenta a estrutura disponível no Google Forms, a qual nos permite facilidade de organização dos instrumentos de coleta, não identificando os sujeitos respondentes, visto que os e-mails e a origem do respondente permanecem inacessíveis ao pesquisador; o número de respondentes é facilmente monitorável, para saber o quanto de respostas estão sendo obtidas (permitindo ações 
preventivas de reforço via e-mail para obter maior frequência de respondentes, sendo evidente aqui uma restrição porque podemos estar reforçando o convite para quem já respondeu); e a facilidade em receber os dados tabulados na forma de uma planilha digital. O relatório gerado pelo Google
Forms, no caso de questões fechadas, já vem previamente tabulado e expresso no formato de gráfico de barras. Isto facilita muito para o pesquisador nas suas análises. A Figura 1 apresenta um exemplo de questões colocadas para o gestor no formulário online.

Figura1 - Questionário criado no Google Forms

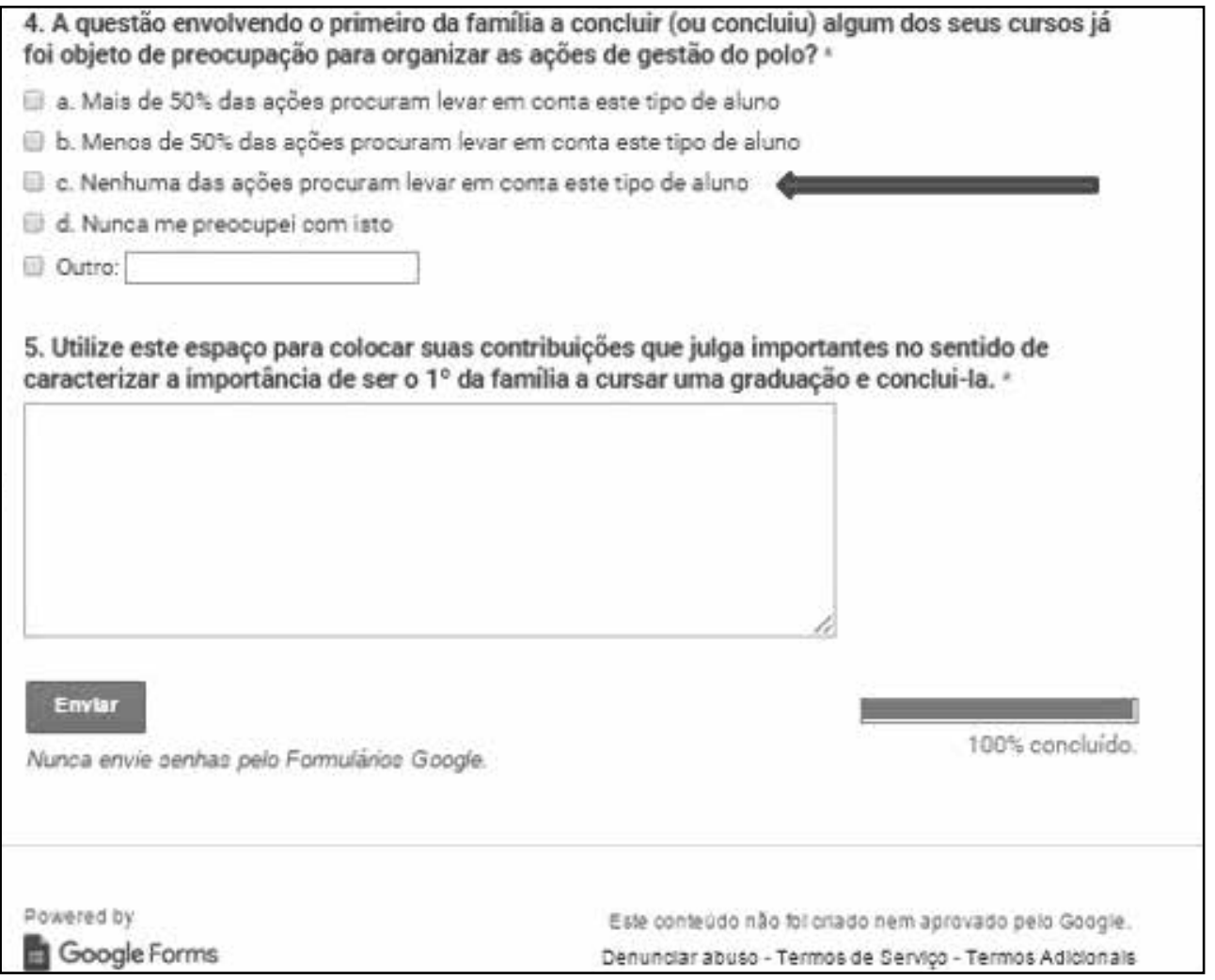

Fonte: Elaborado pelos autores deste artigo.

Para poder tirar partido da estrutura digital do instrumento é muito importante que o pesquisador organize o planejamento das questões a serem disponibilizadas online, identificando o tipo de resposta esperada no caso das questões fechadas. A escolha simples é identificada por um círculo nas opções, e as questões fechadas por um quadradinho (vide destaque na Figura 1). Procuramos colocar poucas questões abertas e ofertar uma lista de opções de resposta incluindo a alternativa "outras", no caso do respondente não se sentir representado na lista ofertada. A razão disto foi evitar a perda de foco em razão do objetivo da investigação, que busca saber o que mudou na vida do egresso nos aspectos pessoal, sociocomunitário, financeiro, profissional e familiar. Para garantir que não havia uma indução nas respostas e sim garantia de foco nas questões, os instrumentos foram enviados, por e-mail, para 3 (três) especialistas no assunto EaD, para receber suas percepções acerca das questões e suas opções. O roteiro/instrumento de coleta de dados foi submetido a validade de conteúdo, que é uma avaliação subjetiva, porém sistemática, sendo que o pesquisador, ou outra pessoa, examina se os itens do instrumento envolvem de forma adequada o domínio do constructo medido (MALHOTRA, 2006). Depois desta etapa foi realizada ainda uma rodada de análise, reunião presencial com especialistas em validação de instrumentos desta natureza e, ao final, observadas as recomendações 
recebidas. Depois escolhemos um grupo de alunos (não participantes da amostra) para verificar se os instrumentos funcionavam como desejado. Todos os sujeitos que participaram da pesquisa obtiveram explicações sobre o estudo através do Termo de Consentimento Livre Esclarecido (TLEC), concordando com os procedimentos e objetivos da coleta de dados. Além disso, o anonimato dos sujeitos participantes desta pesquisa foi respeitado durante a aplicação do processo de validação. Este aspecto, relacionado aos procedimentos éticos da pesquisa, é fundamental para que se faça coleta de dados, qualquer que seja a fase em que se encontra a pesquisa. Cada universidade possui suas diretivas no que concerne à condução das pesquisas. No caso desta investigação, o projeto de pesquisa, após sua defesa e aprovação, em comissão constituída por professores das universidade e avaliadores externos, foi enviado para a comissão científica da unidade para apreciação. Depois de devidamente avaliado e registrado no sistema interno de gerenciamento de pesquisa da universidade (SIPESQ) como "aprovado", partiu-se para o campo. A Figura 2 apresenta um recorte para exemplificar o texto relacionado ao planejamento do questionário enviado aos revisores.

Figura 2 - Planejamento das questões do questionário online

7. Pela sua experiência e observação do cotidiano dos alunos deste polo, com relação ao $1^{\circ} \mathrm{da}$ família, qual (ou quais) das alternativas abaixo melhor caracterizam o efeito do curso na sua vida pessoal:(questão de escolha múltipla)

a. Demonstram mais confiança para realizar projetos de vida

b. Sentem-se modelo e inspiração para os demais familiares

c. Sentem-se modelo e inspiração para os demais amigos

d. Tornaram-se mais solidários

e. Não notei diferença

f. Não sei identificar, não possuo estes dados.

8. Pela sua experiência e observação do cotidiano dos alunos deste polo, com relação ao $1^{\circ} \mathrm{da}$ família, qual (ou quais) das alternativas abaixo melhor caracterizam o efeito do curso na sua vida profissional:(questão de escolha múltipla)

a. Melhoria na sua renda pessoal

b. Melhoria na renda familiar

c. Não notei diferença

d. Não sei identificar, não possuo estes dados.

9. Pela sua experiência e observação do cotidiano dos alunos deste polo, com relação ao $1^{\circ} \mathrm{da}$ família, qual (ou quais) das alternativas abaixo melhor caracterizam o efeito do curso na sua formação educacional:(questão de escolha múltipla)

a. Manifestaram desejo de fazer um curso de extensão na UAB

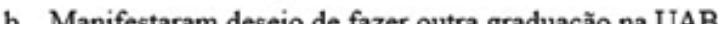

Fonte: Elaborado pelos autores deste artigo.

Esse é um procedimento padrão observado nas pesquisas do ARGOS: o cuidadoso trabalho de organização dos instrumentos de coleta de dados, o qual também é observado no caso de roteiros para entrevistas semiestruturadas. Esta sistemática implica em investimento de tempo e sua inclusão por ocasião do planejamento da pesquisa. Este processo provém da adaptação de procedimentos relaciona- dos à pesquisa quantitativa, em que buscamos a supervisão de um estatístico e outro colega experiente em trabalhos de caráter quali-quanti para assegurar que as questões possuam uma estrutura na qual as variáveis não sejam misturadas, comprometendo a análise dos dados e sua interpretação. Um exemplo disto pode ser observado na Figura 2, onde aparece a pergunta relacionada aos aspectos pessoal, profis- 
sional e de formação. Buscou-se separar bem o foco e disponibilizar alternativas alinhadas aos achados indicados na literatura e devidamente adaptados ao nosso contexto nacional. Isto é importante para facilitar a análise. $\mathrm{O}$ balanceamento entre manter $\mathrm{o}$ foco e evitar a condução é obtido com a validação por especialistas.

Para análise das questões abertas o grupo adota a Análise Textual Discursiva (ATD) proposta por Moraes e Galiazzi (2007). Na ATD temos dois aspectos importantes a considerar: a descrição e a interpretação do que é escrito pelo respondente. A descrição implica num olhar detalhado e atento para quem está lendo de forma minuciosa o processo da análise dos dados. A unitarização dos textos, a fim e identificar as categorias para análise, é um processo exaustivo e trabalhoso. Novamente, no ARGOS adotamos como ferramenta de auxílio a tal tarefa o software online Wordle, que produz uma nuvem de palavras a partir da porção de texto enviada. A Figura 3 apresenta um exemplo de nuvem de palavras produzida.

Figura3 - Nuvem de palavras criada

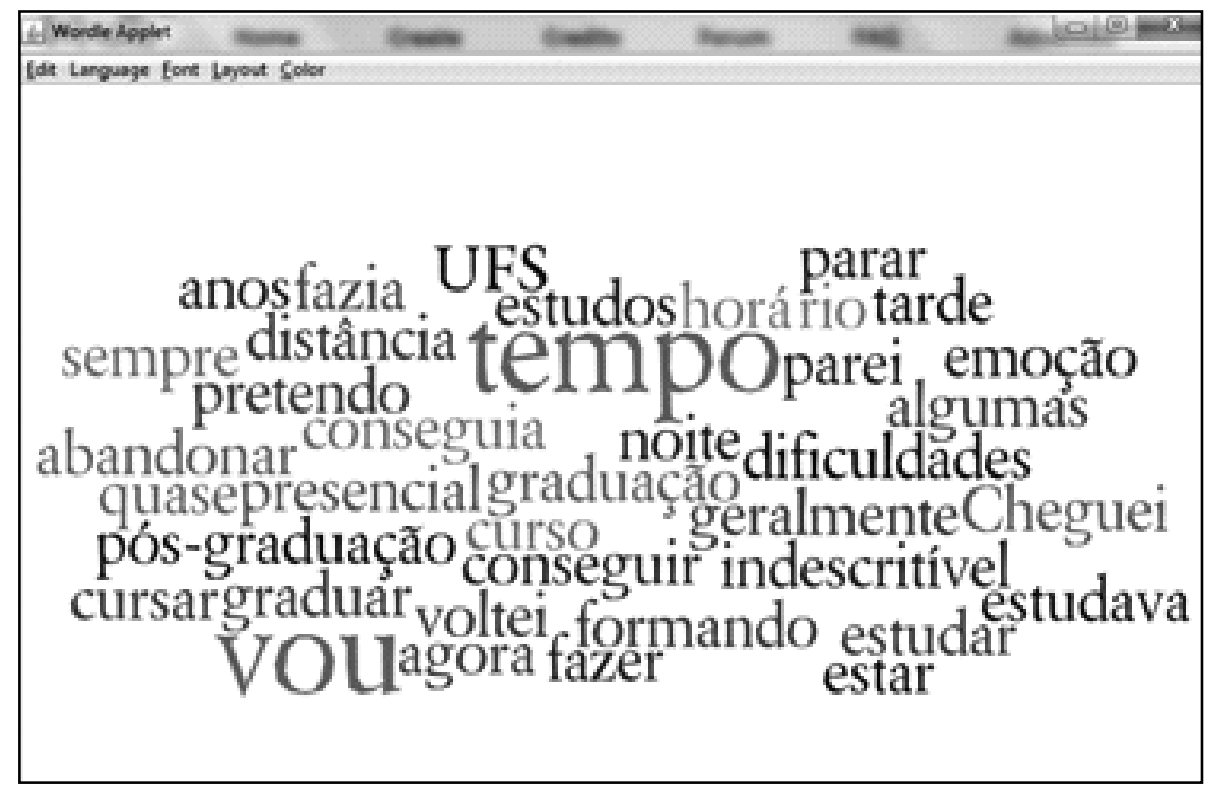

Fonte: Elaborado pelos autores deste artigo.

A metodologia associada à ATD implica em estabelecer categorias para análise dos dados a fim de poder subsidiar as conclusões. Tínhamos agrupamentos a priori que, como de praxe, foram reescritas gerando quatro categorias: cidadania (sentimento de pertencimento e estado de direito), ampliação da educação familiar, aumento da renda familiar e ampliação da formação.

Com os dados levantados nesta fase piloto observou-se a importância da participação do tutor na busca de informações relacionadas ao trabalho com o aluno. São os tutores que trabalham diretamente com o cotidiano dos alunos e possuem as informações que nos permitem traçar o cenário de articulações estabelecidas entre a proposta pedagógica do curso, atividades e construções indivi- duais e coletivas. Assim sendo, quem deseja fazer investigações envolvendo oferta de EaD precisa considerar isto na coleta dos dados. No piloto, os tutores mostram possuir as informações relacionadas aos alunos, e não o coordenador do Polo. $\mathrm{O}$ gestor atua na parte gerencial e organizacional. Sendo que, no caso da UAB, existem processos em nível federal que determinam as diretrizes de atuação, deixando pouca margem a mudanças nos processos gerenciais.

O instrumento permite a identificação dos elementos associados às categorias e comportaram-se da forma esperada. Os instrumentos permitem ao aluno expressar experiências, vivências e mudanças ocorridas na sua condição pessoal, profissional e sociocultural. A UAB em Sergipe permitiu a reali- 
zação do sonho de voltar a estudar e de prosseguir com os estudos a pessoas que hoje se sentem aptas a participar da vida social e profissional; possibilitou que pessoas compatibilizassem suas rotinas de trabalho com todas as atividades pedagógicas, a partir da determinação e organização do tempo pelo sujeito.

As ferramentas selecionadas para operacionalização da pesquisa mostraram-se eficazes (Google Forms e seus relatórios), e o Wordle como elemento de organização e validação das categorias a priori.

ATD e suas etapas puderam ser devidamente compreendidas, permitindo que resultados emergentes nos incentivam a acreditar que na ampliação da investigação haverá repetição dos dados do ENADE, apontando para massiva inclusão de primeiros da família no ensino superior modalidade EaD.

Os trabalhos correlatos e os relatórios gerados nos cursos ofertados na UAB-Sergipe apontam similaridades nas oportunidades relacionadas ao acesso à educação superior. Buscar-se-á em nova etapa da investigação ampliar a aplicação dos instrumentos de forma exaustiva para todos os polos. Isto fará com que o estudo seja mais abrangente no que tange à generalização dos resultados por ora evidenciados e que se aliam ao já identificado na literatura no que concerne à melhora da autoestima, melhora na renda familiar, sentir-se modelo para amigos e familiares, aumento na responsabilidade como agente inspirador de mudanças no seu contexto familiar e grupo social, aumento das possibilidades de trabalho, desejo de continuar estudando. Embora o sonho da pós-graduação ainda seja longínquo para a maioria. Quando alguém faz um curso universitário e é o primeiro na família, ele é um vetor de cultura no contexto familiar. A família mobiliza-se para que ele possa ter condições. Relatos mostram que as famílias acompanham de perto os estudos e se beneficiam disto indiretamente.

$\mathrm{Na}$ modalidade EaD amplia-se o conjunto de suporte necessário para que ao aluno não evada e persista nos seus estudos, uma vez que a modalidade de e-learning pressupõe pré-requisitos de infraestrutura e de fluência digital, questões aqui não abordadas. Ou seja, buscamos focar nos egressos, aqueles que tiveram sucesso, e o que isto trouxe de mudanças nas suas vidas. Desconsiderou-se tratar questões nos instrumentos relacionadas a projeto pedagógico, avaliação da qualidade dos cursos realizados, condições no polo, em casa e outros. Ao perguntar ao tutor (e replicamos as perguntas aos alunos) se ele recebeu ajuda material, emocional ou pedagógica, buscamos localizar os fatores que permitissem identificar nestes alunos algo diferente com relação àqueles que não eram os primeiros na família. Se eles se destacavam pelo comprometimento, perseverança e luta em superar suas deficiências conjecturais, cognitivas e emocionais. Buscou-se verificar se obtiveram ajuda material de professores, tutores ou colegas nos polos; o sentido destas perguntas mostra o envolvimento da comunidade do polo na formação dos sujeitos. Muitos alunos se hospedam na casa do tutor, do professor, para poder participar de atividades no polo. Recebem alimentação e abrigo como forma de incentivo.

A partir desses resultados observamos que apenas os questionários fornecem uma percepção parcial da riqueza do efeito na construção da cidadania destas pessoas. A realidade encontrada no estado de Sergipe é muito aquém dos índices encontrados nas regiões desenvolvidas do país. A falta de escolarização superior impacta negativamente o processo de desenvolvimento social e o nível de empregabilidade da região, tendo como decorrências impactos negativos no estabelecimento da cidadania na sociedade sergipana. A educação superior, ofertada na modalidade $\mathrm{EaD}$, é entendida no contexto desta investigação como um agente potencial de mudança social, ampliando a questão de formação, principalmente a partir do olhar voltado à repercussão e à quebra de padrões com o primeiro da família a conseguir uma graduação de nível superior no Nordeste brasileiro.

Segundo Netto, Giraffa e Faria (2010, p. 09) a EaD é uma alternativa tecnológica que se apresenta em nível mundial e, especificamente na sociedade brasileira, como um "caminho privilegiado de democratização da educação e que, muito pode colaborar para a humanização do indivíduo, para a formação do cidadão e para a constituição de uma formação de uma sociedade mais igualitária e justa".

A EaD ainda enfrenta críticas e resistência de setores tradicionais da educação, como aqueles 
de cunho positivista, marcados pela lógica formal, que criticam o EaD "no que diz respeito ao seu conceito ser/estar associado com baixa qualidade de ensino ou ao atributo de oferecer cursos 'sem validade"”, com origem atribuída a fatores como: "cursos ofertados por instituições sem credenciamento específico para atuar em EaD e aquelas que optaram por oferecer cursos para produção em 'massa' de certificados sem o devido compromisso com a aprendizagem efetiva de seus alunos" (NETTO; GIRAFFA; FARIA, 2010, p. 08, grifo do autor).

Apesar dessas críticas, que não são de todo despropositadas, a EaD é uma realidade, vem ocupando espaços e revelando-se como um instrumento capaz de propiciar a efetivação do direito humano fundamental à educação e ao exercício da cidadania.

\section{Considerações Finais}

Mesmo sendo ainda objeto de críticas, é crescente a aposta e o investimento do poder público e da iniciativa privada na EaD, como uma modalidade de educação que vem se revelando em uma verdadeira quebra de paradigma na educação, com a implementação de método (s) de aprendizagem específico (s) e importante mecanismo capaz de promover a inserção social. Atualmente, muitas das práticas pedagógicas tipicamente associadas à EaD são adotadas em curso presenciais. No Brasil, devido à normatização que rege a oferta de cursos de graduação virtuais, a EaD caracteriza-se pelo modelo blended (misturado), onde atividades são realizadas no ambiente virtual e outras são presenciais, usando os recursos de infraestrutura e de pessoal dos polos.

Vislumbramos, assim, o papel emancipatório da UAB em formar cidadãos ativos, participativos e capazes de romper com um processo natural de apatia e exclusão social a partir da formação do chamado $1^{\circ}$ graduado da família ou first in the $F a$ mily, momento em que esse "novo" cidadão passa a desempenhar um papel de modelo, exemplo a ser seguido por seus familiares e até quem sabe pelos que o circulam, operando uma verdadeira quebra no paradigma intergeracional, fazendo com que as gerações seguintes, naturalmente, a partir do pri- meiro graduado da família, adquiram o anseio ou até a concretização de um status socioeconômico superior aos dos seus ascendentes, e, consequentemente, sendo fonte de inspiração e meta para superação para seus descendentes.

Por fim, a racionalidade discursiva e dialética habermasiana deve estar presente em todo o processo pedagógico da $\mathrm{EaD}$, visto que, assim como fazia Sócrates com a maiêutica, a verdade, o conhecimento ou a formação não deve ser algo imposto de forma acrítica, mas sim construído a partir do diálogo, com todas as suas premissas corolárias, argumentação e contra-argumentação, e com a utilização de todos os recursos mediáticos que lhe são inerentes, como debates, discussões em chats, fóruns, troca de mensagens, vídeos, links de apoio, dentre outros recursos. À medida que se ofertam novas possibilidades associadas às tecnologias digitas, maiores serão as possibilidades e os desafios criativos a serem enfrentados pelos docentes e discentes no seu fazer pedagógico.

O estudo realizado ofertou elementos importantes, que julga-se pertinentes de compartilhar com a comunidade de investigadores interessados no tema de acessão, inclusão e Educação a Distância. Pode-se destacar o compartilhamento do processo e organização de instrumentos de pesquisa em abordagem qualitativa, trazendo processo de validação oriundos da investigação quantitativa adotado no nosso grupo de pesquisa e que tem sido sistematicamente utilizado em diversas investigações. Espera-se colaborar para as reflexões relacionadas ao rigor de processos relacionados à abordagem qualitativa na inserção das tecnologias digitais e seus recursos. Aqui organizamos os instrumentos com uso do Google Forms por questões de oportunidade. Em outras investigações, os instrumentos foram organizados usando Qualtrics, que permite aos usuários fazer coleta de dados on-line. A grande diferença reside, se comparado ao Google Forms e assemelhados, no tipo de resultados e análises que esta ferramenta nos permite realizar, como, por exemplo, análise estatística inferencial.

É importante trazer a questão da discussão da importância do $1^{\circ}$ da família para o âmbito da UAB, especialmente num estado nordestino como o de Sergipe, com tantas restrições socioeconômicas e baixo índice de alunos frequentando a educação 
superior se comparado a outros estados do Norte/ Nordeste e o restante do país.

Além disso, este estudo pode auxiliar gestores públicos a refletirem acerca da importância da oferta de graduação virtual na ampliação dos direitos das pessoas ao acesso à educação superior, a qual funciona como agente potencialmente transformador da vida das pessoas.

[...] a racionalidade limita-se ao modo como o sujeito isolado se orienta em função dos conteúdos das suas representações e dos seus enunciados [...] entendemos o saber como algo transmitido de forma comunicacional, a racionalidade limita-se à capacidade de participantes responsáveis em interações de se orientarem em relação a exigência de validade que assentam sobre o reconhecimento intersubjetivo. A razão comunicativa encontra seus critérios no procedimento argumentativo da liquidação direta ou indireta de exigências de verdade proposicional, justeza normativa, veracidade subjetiva e coerência estética. (HABERMAS, 1990, p. 291).

\section{REFERÊNCIAS}

ALBERT, Cecilia. Higher education demand in Spain: The influence of labor market signals and family background. Higher Education, n. 40, p. 147-162, 2000.

ARISTÓTELES. A Política. São Paulo: Escala, 2008. (Coleção Mestres Pensadores).

BOURDIEU, Pierre. Le champ scientifique. Tradução de Paula Montero. Actes de Ia Recherche en Sciences Sociales, n. 2-3, p. 88-104, jun. 1976.

BUKOSKI, Beth Em. Common challenges and diverse experiences: first-in-their-family college students' narratives. 2012. Dissertation (Doctor of Philosophy) - The University of Texas at Austin, 2012.

ESTÊVÃO, Carlos Alberto Vilar. Educação, justiça e direitos humanos. Educação e Pesquisa, São Paulo, v. 32, n. 1, p. 85-101, jan./abr. 2006. Disponível em: <http://www.scielo.br/pdf/ep/v32n1/a06v32n1.pdf >. Acesso em: 24 ago. 2015.

FLICKINGER, Hans-Georg. Autonomia e reconhecimento: dois conceitos-chave na formação. Educação, Porto Alegre, v. 34, n. 1, p. 7-12, jan./abr. 2011.

GIBBS, Grahan. Análise de dados qualitativos. Trad. Roberto Cataldo Costa. Porto Alegre: Artmed, 2009.

GIRAFFA, Lucia M.M. A formação de professores para trabalhar com Educação a Distância: requisitos e implicações. In: ENCONTRO REGIONAL DE ESTUDANTES DE MATEMÁTICA DO SUL, 16., 2010, Porto Alegre. Anais eletrônicos... Porto Alegre: EDIPUCRS, 2010. v. 1. p. 1-5. Disponível em: <http://www.pucrs.br/edipucrs/ erematsul/.../resumo_LuciaGiraffax.pdf $>$. Acesso em: 20 maio 2012.

GOFEN, Anat. Family capital: how first-generation higher education students break the intergenetational cycle. Family Relations, n. 58, p. 104-120, Feb. 2009.

HABERMAS, Jürgen. O discurso filosófico da modernidade. Lisboa: Dom Quixote, 1990.

. La inclusión del otro. Barcelona: Piados, 1999.

HERMANN, Nadja. Validade em educação: intuições e problemas na recepção de Habermas. Porto Alegre: EDIPUCRS, 1999. (Coleção Filosofia, n. 93).

HONNETH, Axel. Crítica del agravio moral: patologías de la sociedad contemporánea. Trad.: Peter Storandt Diller. Buenos Aires: Fondo de Cultura Económica/Universidad Autónoma Metropolitana, 2009.

KANT, Immanuel. Resposta à pergunta: que é o esclarecimento? Trad. Luiz Paulo Rouanet. 2008. Disponível em: $<$ http://pt.scribd.com/doc/61427661/KANT-Immanuel-Resposta-a-pergunta-Que-e-Esclarecimento $>$. Acesso em: 20 jul. 2015.

KHUN, Thomas. Estrutura das revoluções científicas. São Paulo: Perspectiva, 1978.

MALHOTRA, Naresh K. Pesquisa de marketing: uma orientação aplicada. 4. ed. Porto Alegre: Bookman, 2006. MORAES, Roque; GALLIAZZI, Maria do Carmo. Análise textual discursiva. Ijuí, RS: Editora Unijuí, 2007. 
NETTO, Carla; GIRAFFA, Lúcia; FARIA, Elaine. Graduações a distância e o desafio da qualidade. Porto Alegre: EDIPUCRS, 2010.

PLATÃO.A República (Da Justiça). São Paulo: Edipro, 2006.

PRESTES, Nadja Hermann. Educação e racionalidade: conexões e possibilidades de uma razão comunicativa na escola. Porto Alegre: EDIPUCRS, 1996.

UNIVERSIDADE ABERTA DO BRASIL (UAB). O que é. Disponível em: <http://uab.capes.gov.br/index.php/ sobre-a-uab/o-que-e>. Acesso em: 05 jan. 2014.

YIN, Robert K. Estudo de caso: planejamento e métodos. 4. ed. Trad. Daniel Grassi. Porto Alegre: Bookman, 2001.

Recebido em: 01.07.2015

Aprovado em: 15.10 .2015 